\title{
Expression and clinical significance of programmed death ligand 1 in nasopharyngeal carcinoma
}

\author{
YUAN QU ${ }^{1 *}$, DI WANG ${ }^{2 *}$, LIN YANG $^{3}$, HUI-YING LIU ${ }^{4}$, WEI CUI ${ }^{2}$ and YI-QUN CHE ${ }^{2}$ \\ Departments of ${ }^{1}$ Radiation Oncology, ${ }^{2}$ Clinical Laboratory and ${ }^{3}$ Pathology, National Cancer Center/Cancer Hospital, Chinese \\ Academy of Medical Sciences and Peking Union Medical College, Beijing 100021; ${ }^{4}$ Department of Clinical Laboratory, \\ Beijing Chaoyang District Sanhuan Cancer Hospital, Beijing 100122, P.R. China
}

Received December 2, 2017; Accepted May 16, 2018

DOI: $10.3892 / \mathrm{mco} .2018 .1633$

\begin{abstract}
Nasopharyngeal carcinoma (NPC) has the highest incidence of all types of head and neck cancer in China. The present study aimed to investigate the association between the expression of programmed death ligand 1 (PD-L1) in NPC tissues and clinicopathological features, as well the outcomes for NPC patients. In addition, the association between tissue expression of PD-L1 and immune components in peripheral blood was assessed. The expression of PD-L1 was determined by immunohistochemistry, while immune indexes were determined by ELISA and flow cytometry. The positive expression rate of PD-L1 in NPC patients was $29.2 \%$, and the PD-L1 expression levels were associated with distant metastasis $(\mathrm{P}=0.010)$ and the $\mathrm{T}$-stage of the primary tumor $(\mathrm{P}=0.032)$. The expression of PD-L1 was associated with the distant metastasis-free survival of NPC patients $(\mathrm{P}=0.006)$. In addition, a statistically significant association of PD-L1 expression with Epstein-Barr virus viral capsid antigen IgA (EBV VCA-IgA; $\mathrm{P}=0.046)$ and with $\mathrm{CD} 3^{-} \mathrm{CD} 19^{+}$cells $(\mathrm{P}=0.014)$ was identified. These results indicated that $\mathrm{PD}-\mathrm{L} 1$ may be a potential prognostic biomarker for NPC patients, and that EBV VCA-IgA and $\mathrm{CD}^{-}{ }^{-} \mathrm{CD} 19^{+}$cells may be useful for predicting PD-L1 expression when its levels cannot be detected due to the lack of a tumor tissue sample.
\end{abstract}

Correspondence to: Professor Yi-Qun Che, Department of Clinical Laboratory, National Cancer Center/Cancer Hospital, Chinese Academy of Medical Sciences and Peking Union Medical College, 17 Panjiayuan Nanli, Chaoyang District, Beijing 100021, P.R. China

E-mail: cyq@cicams.ac.cn

${ }^{*}$ Contributed equally

Key words: nasopharyngeal carcinoma, programmed death ligand 1 , distant metastasis

\section{Introduction}

Nasopharyngeal carcinoma (NPC) is a malignant tumor type that arises from the epithelial surface of the nasopharynx, and has the highest incidence of all types of head and neck cancer in China. Men are most frequently affected by NPC, typically at an age of 40-50 years. Causative factors for NPC include heredity, Epstein-Barr virus (EBV) and environmental factors (1). Primary NPC lesions are differentiated or undifferentiated non-keratinizing carcinomas, which are sensitive to radiotherapy. As the radiotherapy response rate is $85 \%$, it is the preferred treatment for NPC (2). However, due to the variable clinical manifestations of NPC, misdiagnosis and missed diagnosis occur frequently. The majority of patients are diagnosed in the late stages of the disease, when the tumor has invaded the surrounding tissues; the higher local recurrence rates and distant metastasis rates associated with late-stage NPC lead to decreased overall survival (3). Therefore, a novel and effective method for the clinical diagnosis of NPC is urgently required.

The occurrence of NPC is associated with EBV infection, and immune function serves an important role in the development of NPC. The expression of programmed death ligand 1 (PD-L1) has been reported as a reliable prognostic factor for various types of malignancy. However, the association between the expression of PD-L1 and the clinicopathological factors and prognosis of NPC patients remain to be fully elucidated.

PD-L1 is a member of the B7 family and the protein consists of 290 amino acids (4). The extracellular domain of PD-L1 binds to programmed cell death protein 1 (PD-1), which is expressed on the surface of activated $\mathrm{T}$ lymphocytes. The PD-1/PD-L1 pathway mediates negative co-stimulatory signals to effectively inhibit T-cell function and proliferation, and decrease the secretion of cytokines, including interleukin (IL)-2, IL-10 and interferon (IFN)- $\gamma$. The pathway serves an important role in the immunomodulation of various diseases and pathological processes, including tumor immunity, transplantation immunity, viral infection and autoimmunity $(5,6)$. The abnormal expression of PD-L1 in numerous types of malignant tumor, including melanoma, lung cancer, esophageal cancer, colorectal cancer, breast cancer and glioma, is associated with tumor invasion and metastasis, decreased tumor infiltration by $\mathrm{T}$ lymphocytes, poor prognosis and reduced survival time (7). 
NPC is characterized by prevailing EBV infection and the presence of immune cell infiltration around the cancer lesions (8). EBV-DNA exists as cell-free fragments in the serum of infected patients. Lo et al (9) identified that EBV-DNA was detectable in the plasma of $96 \%$ of the NPC patients assessed, and observed that serum EBV-DNA levels in patients with advanced-stage disease were significantly higher than that in patients with early-stage disease, suggesting that serum EBV-DNA levels may be positively correlated with the tumor burden. EBV early antigen (EA)-immunoglobulin (Ig)A and EBV viral capsid antigen (VCA)-IgA are markers of viral infection that are commonly used in the clinical screening and auxiliary diagnosis of NPC, and indicate the risk of NPC development. It has been identified that NPC patients display aberrations in peripheral blood lymphocyte subsets (10); this abnormal immune status may be due to the abnormal cellular immune response in NPC and may be associated with the immune response to EBV infection. However, the possible underlying association between PD-L1 and alterations in the immune components in the peripheral blood of NPC patients has remained to be determined.

In the present study, the expression of PD-L1 was examined in NPC tissues of patients from northern China, and the association between PD-L1 expression levels and the clinicopathological parameters was assessed. In addition, the lymphocyte subsets, EBV-DNA and EBV antibodies in peripheral blood were assessed in order to provide potential markers for the diagnosis and treatment of NPC.

\section{Materials and methods}

Patients and clinical data. Tissue specimens and peripheral blood were collected from 96 NPC patients, including 72 males (median age, 48 years; range, 13-82 years) and 24 females (median age, 41.5 years; range, 11-67 years). Patients were recruited at the National Cancer Center/Cancer Hospital, Chinese Academy of Medical Sciences (Beijing, China). The patients were enrolled according to the following criteria: i) Radiotherapy was received; ii) complete clinical data were available; and iii) no other malignant diseases, active hepatitis or diabetes were diagnosed. The retrospective study was approved by the Institutional Review Board of the Cancer Hospital, Chinese Academy of Medical Sciences (Beijing, China. The trial registration number was NCC2016YJC-10). Written, informed consent was provided by all patients prior to enrollment in the study.

Immunohistochemical analysis. The paraffin-embedded tissues were cut into 4- $\mu \mathrm{m}$ sections, dewaxed and then rehydrated with a graded ethanol series. To quench endogenous peroxidase activity, the sections were incubated with $3 \%$ $\mathrm{H}_{2} \mathrm{O}_{2}$ at room temperature for $20 \mathrm{~min}$. For antigen retrieval, the sections were heated in ethylene diamine tetraacetic acid buffer ( $\mathrm{pH}, 8.0$ ) for $2 \mathrm{~min}$ using a pressure cooker. The slides were blocked with normal goat serum (Ready-to-use; cat. no. ZLI-9022; OriGene Technologies, Beijing, China) at $37^{\circ} \mathrm{C}$ for $20 \mathrm{~min}$. Samples were incubated with rabbit-monoclonal anti-PD-L1 antibody (dilution, 1:200; cat. no. ab205921; Abcam, Cambridge, UK) and mouse monoclonal anti-P16 antibody (Ready-to-use; cat. no. 705-4713; Ventana Medical
Systems, Inc., Tucson, AZ, USA) overnight at $4^{\circ} \mathrm{C}$. Incubation with secondary antibody and staining was performed using an immunohistochemical staining kit (cat. no. PV-9000; OriGene Technologies) according to the manufacturer's protocol. The immunoreaction was visualized with diaminobenzidine staining, followed by counterstaining with hematoxylin. The primary antibody was replaced with PBS to prepare the negative control sample, and PD-L1-positive slides incubated with the antibodies were used as a positive control.

Percentages of PD-L1-positive tumor cells and staining intensity were independently evaluated by two experienced pathologists who were blinded to the clinical information. They assessed 20 sequential high-power fields $(0.54 \mathrm{~mm}$ diameter per field) using Aperio ImageScope software version 12.3.0 (Leica Biosystems, Wetzlar, Germany) to quantify the staining in the images captured. A proportion of stained cells of $>10 \%$ was considered to indicate a positive expression status, with $>25 \%$ considered as high expression and $10-25 \%$ as low expression.

Lymphocyte subset detection. Venous blood samples were collected from patients prior to radiotherapy and stored with K3EDTA anti-coagulant. The samples were analyzed by flow cytometry using the BD Multitest ${ }^{\mathrm{TM}}$ IMK kit (cat. no. 340503; BD Biosciences, Franklin Lakes, NJ, USA). The CD4/CD8/CD3/CD45 trichromatic fluorescent monoclonal antibodies in the kit were diluted 1:10 and incubated with the samples for $15 \mathrm{~min}$ at room temperature. FACSCanto version 6.1.3 (BD Biosciences) was used to analyze T-lymphocyte subsets, including total $\mathrm{T}$ lymphocytes $\left(\mathrm{CD}^{+} \mathrm{T}\right)$, the $\mathrm{T}$ auxiliary/induced cell subset $\left(\mathrm{CD}^{+}{ }^{+} \mathrm{CD} 4^{+} \mathrm{T}\right)$, the $\mathrm{T}$ suppressor/cytotoxic cell subset $\left(\mathrm{CD} 3^{+} \mathrm{CD} 8^{+} \mathrm{T}\right)$, the ratio of $\mathrm{T}$ auxiliary to suppressor cells $\left(\mathrm{CD}^{+} \mathrm{CD}^{+} / \mathrm{CD}^{+} \mathrm{CD} 8^{+}\right)$, natural killer $(\mathrm{NK})$ cells $\left(\mathrm{CD} 3^{-} \mathrm{CD} 56^{+}\right)$and $\mathrm{B}$ lymphocytes $\left(\mathrm{CD} 3{ }^{-} \mathrm{CD} 19^{+}\right)$.

Detection of EBV infection. ELISA diagnostic kits (Euroimmun, Lübeck, Germany) were applied to detect serum EBV EA-IgA (cat. no. EI 2795-9601 A) and VCA-IgA (cat. no. EI 2791-9601 A) antibodies. The kits were used according to the manufacturer's protocol, and the antibody concentrations were determined with a standard curve. EBV-DNA was detected using the Epstein-Barr Virus (EBV) Polymerase Chain Reaction (PCR) Fluorescence Detection kit (cat. no. DA-D065; DaAn Gene Co., Ltd., Guangzhou, China) according to the manufacturer's protocol, with a Roche LightCycler $^{\circledR}$ 480II (Roche Diagnostics, Basel, Switzerland).

Follow-up. Following the completion of radiotherapy and chemotherapy, the NPC patients were followed up every 3 months, which included thoracic and abdominal computed tomography scans, and nasopharyngeal and cervical magnetic resonance imaging (MRI). When a nasopharyngeal mass was identified on MRI, electro-epipharyngoscopy and biopsy were performed. Fine-needle aspiration cytology was applied when cervical lymph node enlargement was identified. Follow-up continued until June 1, 2017; the last time-point for the patient with the latest enrolment. Distant metastasis-free survival (DMFS) was defined as the time from the beginning of radiotherapy to the identification of metastasis, or until the 
A

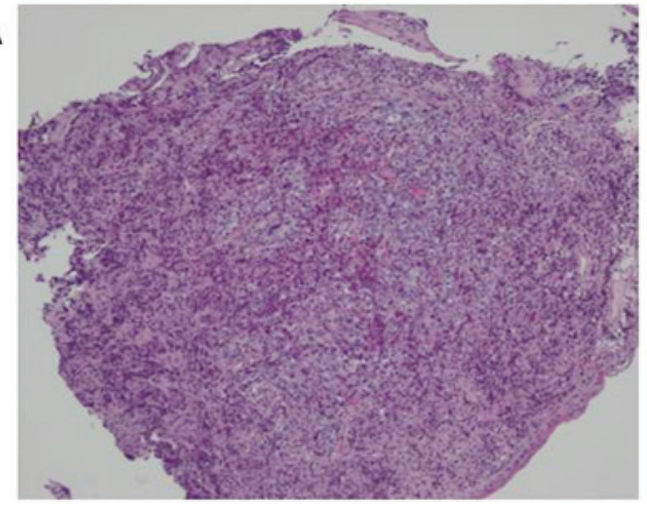

B

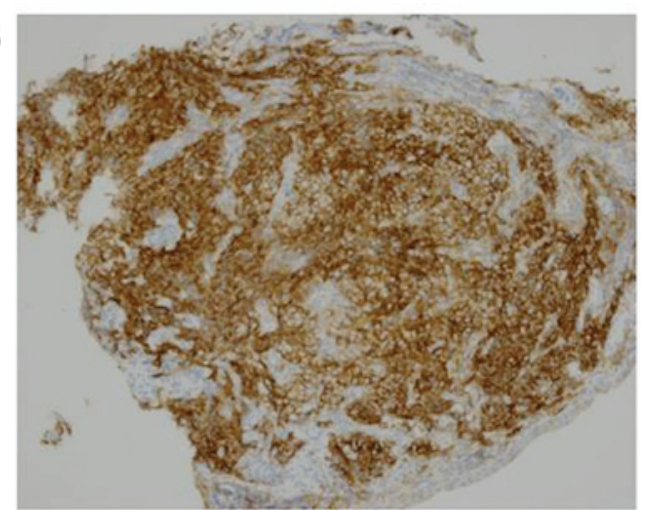

Figure 1. Representative images of H\&E staining and immunohistochemical staining for PD-L1 in tumor samples from NPC patients. (A) H\&E staining of an NPC tumor sample (magnification, x100). (B) Representative immunohistochemical image of an NPC tumor sample with expression of PD-L1 (magnification, x100). H\&E, hematoxylin and eosin; PD-L1, programmed death ligand 1; NPC, nasopharyngeal carcinoma.

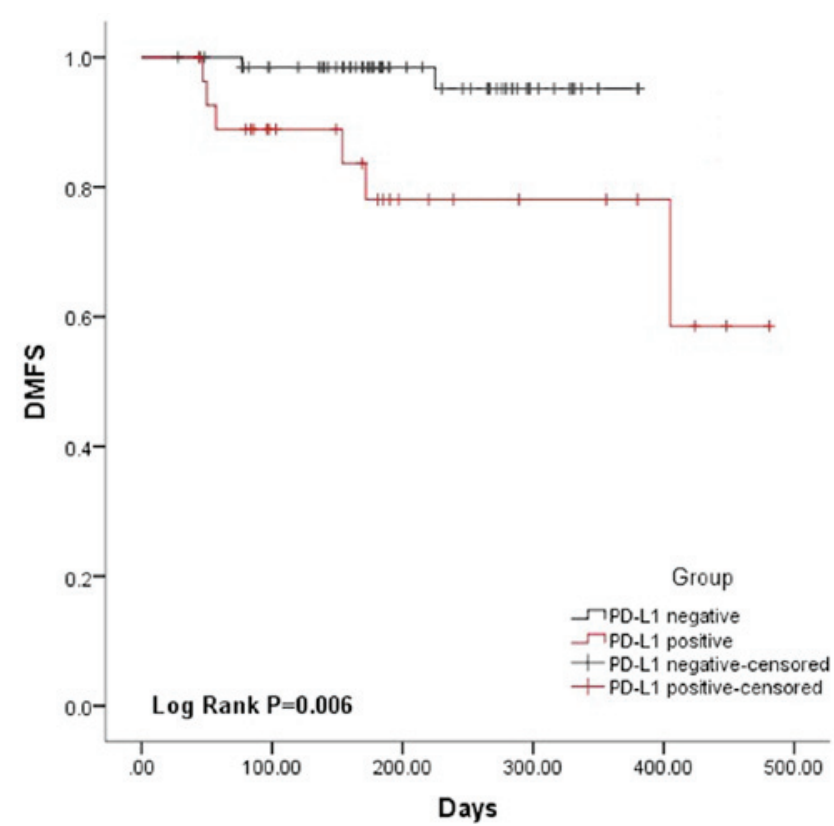

Figure 2. DMFS survival analysis of nasopharyngeal carcinoma patients. Kaplan-Meier survival curves for patient DMFS time stratified by PD-L1 expression levels $\left(\chi^{2}=7.485, \mathrm{P}=0.006\right)$. DMFS, distant metastasis-free survival; PD-L1, programmed death ligand 1.

last follow-up. The distant metastases were all detected after 1 year's follow-up.

Statistical analysis. SPSS version 22.0 software (IBM Corp., Armonk, NY, USA) was used for statistical analysis. Discrete variables were compared using Fisher's exact test, $\chi^{2}$ test and Wilcoxon $\mathrm{W}$ test, continuous variables were compared using Student's t-test, Mann-Whitney U and Kruskal-Wallis H test. Survival data were analyzed using the Log-rank test. $\mathrm{P}<0.05$ was considered to indicate a statistically significant difference.

\section{Results}

Expression of PD-L1 protein in NPC patients. The expression of PD-L1 was analyzed in 96 NPC specimens by immunohistochemical staining. The protein was predominantly expressed on the cell membrane (Fig. 1). Immunohistochemical analysis revealed that 28/96 NPC samples (29.2\%) were positive for PD-L1 expression and 68 cases $(70.8 \%)$ were negative.

PD-L1 expression and the clinicopathological features of NPC patients. The association of PD-L1 expression with clinicopathological parameters was assessed to clarify the function of PD-L1 in NPC. No significant associations between PD-L1 expression status and sex, age or histotype classification were identified. However, PD-L1 expression was significantly associated with NPC 1-year distant metastasis $(\mathrm{P}=0.010)$ and the tumor $(\mathrm{T})$-stage of the primary tumor $(\mathrm{P}=0.032)$. No significant association between PD-L1 expression and the AJCC stage (2010) or treatment modality (with or without chemotherapy or before or after radiotherapy) was identified (Table I).

Expression of PD-L1 is associated with the DMFS of NPC patients. The DMFS for the PD-L1-positive and -negative groups is presented in Fig. 2. Patients with a PD-L1-positive status had significantly poorer DMFS $(\mathrm{P}=0.007)$ compared with that of patients with a PD-L1-negative status. The 1-year distant metastasis rate was $2.9 \%$ for PD-L1-negative patients and $21.4 \%$ for PD-L1-positive patients (Table I). Thus, the patients with a PD-L1-positive status were at a significantly higher risk of developing metastasis.

Association of PD-L1 expression status in NPC tissues with $E B V$-DNA and lymphocyte subsets in the peripheral blood. PD-L1 is an immunosuppressive molecule associated with an abnormal immune status in the body. ELISA and qPCR were used to detect the levels of EBV antibodies and EBV-DNA, while lymphocyte subsets were detected using flow cytometric analysis of the peripheral blood of NPC patients. A statistically significant association of $\mathrm{PD}-\mathrm{L} 1$ expression with $\mathrm{EBV}$ VCA-IgA antibodies $(\mathrm{P}=0.046)$ and with $\mathrm{CD}^{-} \mathrm{CD} 19^{+}$cells was identified $(\mathrm{P}=0.014$; Table II).

\section{Discussion}

NPC is associated with EBV infection, poor tumor cell differentiation and sensitivity to chemotherapy. In addition, compared with other types of head and neck squamous cell carcinoma, NPC has a unique geographical distribution, with 
Table I. Association between PD-L1 expression and the clinicopathological features of nasopharyngeal carcinoma patients.

\begin{tabular}{|c|c|c|c|c|c|}
\hline Characteristic & Cases (n) & $\begin{array}{c}\text { PD-L1-negative } \\
(\%)\end{array}$ & $\begin{array}{c}\text { PD-L1-positive } \\
(\%)\end{array}$ & $\chi^{2}$ & P-value \\
\hline Sex & & & & 0.269 & 0.604 \\
\hline Male & 72 & $52(72.2)$ & $20(27.8)$ & & \\
\hline Female & 24 & $16(66.7)$ & $8(33.3)$ & & \\
\hline Age (years) & & & & 1.18 & 0.277 \\
\hline$>46$ & 46 & $35(76.1)$ & $11(23.9)$ & & \\
\hline$\leq 46$ & 50 & $33(66.0)$ & $17(34.0)$ & & \\
\hline Histotype & & & & 1.803 & 0.179 \\
\hline Undifferentiated non-keratinizing carcinoma & 64 & $42(65.6)$ & $22(34.4)$ & & \\
\hline Differentiated non-keratinizing carcinoma & 27 & $22(81.5)$ & $5(18.5)$ & & \\
\hline Poorly differentiated non-keratinizing carcinoma & 5 & $4(80)$ & $1(20)$ & & \\
\hline 1-year distant metastasis & & & & 6.619 & 0.010 \\
\hline No & 88 & $66(75)$ & $22(25)$ & & \\
\hline Yes & 8 & $2(25)$ & $6(75)$ & & \\
\hline Locoregional recurrence & & & & & 0.203 \\
\hline No & 93 & $67(72.0)$ & $26(28.0)$ & & \\
\hline Yes & 3 & $1(33.3)$ & $2(66.7)$ & & \\
\hline AJCC stage (2010) & & & & $3,079.5^{\mathrm{a}}$ & 0.051 \\
\hline I & 4 & $4(100.0)$ & $0(0.0)$ & & \\
\hline II & 7 & $5(71.4)$ & $2(28.6)$ & & \\
\hline III & 48 & $37(77.1)$ & $11(22.9)$ & & \\
\hline IV & 37 & $22(59.5)$ & $15(40.5)$ & & \\
\hline T-stage & & & & $3,054.0^{\mathrm{a}}$ & 0.032 \\
\hline 1 & 13 & $12(92.3)$ & $1(7.7)$ & & \\
\hline 2 & 6 & $4(66.7)$ & $2(33.3)$ & & \\
\hline 3 & 49 & $36(73.5)$ & $13(26.5)$ & & \\
\hline 4 & 28 & $16(57.1)$ & $12(42.9)$ & & \\
\hline N-stage & & & & $3,295.5^{\mathrm{a}}$ & 0.983 \\
\hline 0 & 7 & $5(71.4)$ & $2(28.6)$ & & \\
\hline 1 & 27 & $18(66.7)$ & $9(33.3)$ & & \\
\hline 2 & 46 & $35(76.1)$ & $11(23.9)$ & & \\
\hline 3 & 16 & $10(62.5)$ & $6(37.5)$ & & \\
\hline M-stage & & & & 0.000 & 1.000 \\
\hline 0 & 96 & $68(70.8)$ & $28(29.2)$ & & \\
\hline 1 & 0 & $0(0.0)$ & $0(0.0)$ & & \\
\hline Chemotherapy $^{\mathrm{b}}$ & & & & 0.024 & 0.878 \\
\hline No & 23 & 16 (69.6) & $7(30.4)$ & & \\
\hline Yes & 73 & $52(71.2)$ & $21(28.8)$ & & \\
\hline
\end{tabular}

${ }^{a}$ Wilcoxon $\mathrm{W}$ test. ${ }^{\mathrm{b}}$ With or without chemotherapy before/after radiotherapy. PD-L1, programmed death ligand 1; T, tumor; N, nodes; M, metastasis.

a particularly high incidence in southern China and Southeast Asia (11). After conventional treatment with chemoradiotherapy, the majority of NPC tumor cells are eliminated. The activation of immune cells, including tumor-infiltrating lymphocytes (TILs), is important for the elimination of residual tumor cells. However, a variety of immunosuppressive mechanisms act to reduce the activity of TILs in the tumor microenvironment, resulting in local recurrence and distant metastasis in a number of patients after radiotherapy and chemotherapy $(12,13)$. Once this has occurred, effective treatment options are limited; the majority of patients in this situation choose palliative chemotherapy to prolong their survival period, but the effect is limited. Therefore, identifying how the immune suppression index is associated with the recurrence and metastasis of NPC may assist in improving the prognosis of patients. 
Table II. Correlation of various markers in the serum with PD-L1 expression in tumor tissues.

A, EBV DNA levels in plasma vs. PD-L1 expression

\begin{tabular}{lccr}
\hline Group & PD-L1 negative & PD-L1 positive & $\chi^{2}$ \\
\hline EBV DNA $^{-}$ & 41 & 16 & 0.082 \\
EBV DNA $^{+}$ & 27 & 12 & 0.775 \\
\hline
\end{tabular}

B, EBV antibody levels in serum vs. PD-L1 expression

\begin{tabular}{lccc}
\hline Group & Cases (n) & Median & Mann-whitney U \\
\hline EBV EA-IgA & 67 & & 762.5 \\
PD-L1 negative & 28 & 0.019 & 0.152 \\
PD-L1 positive & & & 0.3405 \\
EBV VCA-IgA & 67 & 2.067 & 694.0 \\
PD-L1 negative & 28 & 1.0155 & 0.046 \\
PD-L1 positive & & & \\
\hline
\end{tabular}

C, Lymphocyte subset levels in plasma vs. PD-L1 expression

\begin{tabular}{|c|c|c|c|c|}
\hline Cell type & Cases (n) & Value $(\%)$ & $\mathrm{t}$ & P-value \\
\hline $\mathrm{CD}^{+} \mathrm{T}$ cells & & & 0.38 & 0.705 \\
\hline PD-L1 negative & 65 & $67.4754 \pm 9.608$ & & \\
\hline PD-L1 positive & 26 & $66.6269 \pm 9.664$ & & \\
\hline $\mathrm{CD}^{+} \mathrm{CD}^{+} \mathrm{T}$ cells & & & 0.39 & 0.697 \\
\hline PD-L1 negative & 65 & $31.0446 \pm 7.672$ & & \\
\hline PD-L1 positive & 26 & $30.3192 \pm 8.814$ & & \\
\hline $\mathrm{CD}^{+} \mathrm{CD}^{+} \mathrm{T}$ cells & & & 0.09 & 0.929 \\
\hline PD-L1 negative & 65 & $31.8554 \pm 9.731$ & & \\
\hline PD-L1 positive & 26 & $31.6654 \pm 7.286$ & & \\
\hline $\mathrm{CD}^{+} / \mathrm{CD}^{+}$ & & & $768.0^{\mathrm{a}}$ & 0.569 \\
\hline PD-L1 negative & 64 & $0.965(0.7575)$ & & \\
\hline PD-L1 positive & 26 & $0.975(0.52)$ & & \\
\hline NK cells & & & -0.741 & 0.460 \\
\hline PD-L1 negative & 64 & $23.5734 \pm 10.0917$ & & \\
\hline PD-L1 positive & 26 & $25.3731 \pm 11.2599$ & & \\
\hline $\mathrm{CD}^{-} \mathrm{CD}^{-} 9^{+}$cells & & & $8.532^{\mathrm{b}}$ & 0.014 \\
\hline PD-L1 negative & 64 & $7.25(5.95)$ & & \\
\hline PD-L1 low expression & 19 & $8.1(6.1)$ & & \\
\hline PD-L1 high expression & 7 & $4.0(2.9)$ & & \\
\hline
\end{tabular}

Values are expressed as the mean \pm standard deviation or median (interquartile range); ${ }^{\mathrm{a}}$ Mann-Whitney U test; ${ }^{\mathrm{b}} \mathrm{Kruskal}-$ Wallis $\mathrm{H}$ test. Normal ranges: $\mathrm{CD}^{+} \mathrm{T}$ cells, $61.1-77.0 \%$; $\mathrm{CD}^{+}{ }^{+} \mathrm{CD} 4^{+} \mathrm{T}$ cells, $25.8-41.6 \%$; $\mathrm{CD}^{+} \mathrm{CD}^{+} \mathrm{T}$ cells, $18.1-29.6 \%$; $\mathrm{CD}^{+} / \mathrm{CD}^{+}$cells, $0.98-1.94 \%$; $\mathrm{NK}$ cells, 8.1-26.6\%; CD3-CD19+ cells, 7.3-18.2\%; EBV EA-IgA, <1.1 S/CO; EBV VCA-IgA, <1.1 S/CO. NK, natural killer; EBV, Epstein-Barr virus; PD-L1, programmed death-ligand 1; VCA-IgA, viral capsid antigen IgA; EA-IgA, early antigen IgA.

PD-L1 is a member of the Ig superfamily with the chromosomal location of 9p24.2, which encodes a 290-amino acid type I transmembrane protein, including an extracellular portion with $\mathrm{IgV}$ and $\mathrm{IgC}$-like domains. Its IgV-like domain interacts with the extracellular $\operatorname{IgV}$ domain of PD-1, and the immune tyrosine motif region of the cytoplasmic tail of the PD-1 molecule serves an important role in the negative regulation of the immune response (14). Under normal physiological conditions, PD-1 maintains the body's immune tolerance as a negative regulator of $\mathrm{T}$-cell proliferation; however, in tumors and viral infection, the overexpressed PD-L1 and PD-L2 on the cell surface interacts with PD-1 on 
the surface of $\mathrm{T}$ cells to inhibit T-cell activation, proliferation and cytotoxicity to the tumor (15). A number of studies have demonstrated that the expression of PD-L1 is increased in numerous types of cancer, including breast cancer (16), renal cell carcinoma (17), ovarian cancer (18) and non-small cell lung cancer (19). The present study investigated the expression of PD-L1 in 96 NPC tumors and identified a PD-L1-positive rate of 29.2\% (28/96). Previous Chinese and international studies regarding PD-L1 expression and clinical significance in NPC have reported conflicting results. Peng et al (20) identified a PD-L1-positive rate of $67.2 \%$ (43/64) in NPC tissue samples. This discrepancy with the results of the present study may be due to differences in the evaluation of PD-L1 staining, as in the present study, staining in $<10 \%$ of the cells was considered to indicate a negative expression status. In addition, NPC has unique regional characteristics. The patients in the present study were from non-high incidence area (northern China) and there may be greater heterogeneity outside high-incidence areas.

To date, a range of studies have confirmed that PD-L1 expression is associated with the prognosis of cancer patients. Shi et al (21) identified that high expression of PD-L1 in colorectal carcinoma was associated with the tumor-nodes-metastasis stage and prognosis. Nomi et al (22) reported that pancreatic cancer patients with PD-L1-positive tumors exhibited a worse prognosis than those with PD-L1-negative tumors. Frigola et al (17) indicated that the expression of PD-L1 was associated with the tumor stage and prognosis in patients with renal cell carcinoma. Li et al (23) reported that high tumor expression of PD-L1 was associated with significantly poorer OS and DFS. Compared with other types of head and neck tumor, NPC has a higher risk of metastasis. Therefore, it is critically important to screen NPC patients who may have a high risk of recurrence and distant metastasis subsequent to conventional radiotherapy and chemotherapy. In the present study, it was identified that the expression of PD-L1 was not associated with sex, age, pathological type or lymph node metastasis, whereas it differed significantly depending on the T-stage of the primary tumor $(\mathrm{P}=0.032)$ and the 1 -year distant metastasis status $(\mathrm{P}=0.01)$, suggesting that $\mathrm{PD}-\mathrm{L} 1-$ positive patients may have a relatively poor prognosis. The result that the association between the expression of PD-L1 and the clinical stage was not statistically significant $(\mathrm{P}=0.051)$ may be due to the small sample size. In addition, at the 1-year follow-up after radiotherapy, the survival analysis demonstrated that the DMFS for patients with tumors with a PD-L1-positive status was lower than that of the patients with tumors with a negative status $(\mathrm{P}=0.006)$.

The occurrence of NPC is highly associated with EBV infection; infection markers including EBV-DNA, as well as EBV EA-IgA and EBV VCA-IgA, have been widely used in the clinical diagnosis. In addition, the detection of $\mathrm{T}$ lymphocyte subsets in the peripheral blood of patients with malignant tumors by flow cytometry may be used to determine the immune status, which is a valuable reference for clinical diagnosis and treatment. The detection of EBV EA-IgA and EBV VCA-IgA antibodies is a common method for the clinical screening for and diagnosis of NPC. The presence of cell-free fragments of EBV-DNA in the serum has recently been identified to be valuable in predicting the prognosis and recurrence risk of NPC (24). In the present study, it was observed that the concentration of EBV VCA-IgA antibody in the serum of PD-L1-positive patients was significantly lower than that of PD-L1-negative patients $(\mathrm{P}=0.046)$, although the levels in each of the two groups were above the normal levels. In addition, the number of $\mathrm{B}$ lymphocytes $\left(\mathrm{CD} 3{ }^{-} \mathrm{CD} 19^{+}\right)$in patients with PD-L1-positive status was significantly lower than that in patients with PD-L1-negative status. A possible explanation is that a PD-1/PD-L1 interaction mediated a negative regulation signal to produce immunosuppression, including the reduced secretion of the cytokines IL-2, IL-10 and IFN- $\gamma$ (5), which may influence the number of serum B lymphocytes and the ability of B cells to produce antibodies subsequent to accepting a viral antigen. However, the specific mechanisms require further study. The present results suggest that the levels of EBV VCA-IgA and $\mathrm{CD}^{-} \mathrm{CD} 19^{+}$cells may be used to predict PD-L1 expression, particularly in cases when PD-L1 cannot be detected due to a lack of a sufficient tissue sample.

In recent years, an increasing number of clinical trials on PD-L1 antibodies have been performed, and clinical remission has been achieved in certain patients with non-small cell lung cancer and renal cell carcinoma (25-27). However, no such trials have been performed on NPC, and targeted immunotherapy of the PD-1/PD-L1 pathway has not been fully evaluated in NPC. In the present study, it was observed that the positive expression rate of PD-L1 in NPC tissues was $29.2 \%$, which was associated with distant metastasis and the T-stage of patients. The DMFS of patients with positive PD-L1 expression status was significantly reduced, suggesting a poor prognosis. Therefore, it may be hypothesized that blocking the PD-1/PD-L1 pathway may be effective as an immunotherapy for NPC. However, the present study was of a retrospective nature and had a small sample size, a short follow-up time and correspondingly a small number of recurrence and metastasis cases. In the future, a prospective study with a larger sample size, performed over a longer period, will be required, to allow for in-depth exploration of the association between PD-1/PD-L1 expression and groups of NPC patients with different prognoses, and to provide a theoretical basis for immunotherapy via the PD-1/PD-L1 pathway.

\section{Funding}

This work was supported by the Chinese Academy of Medical Sciences Innovation Fund for Medical Sciences (grant nos. 2017-I2M-1-013 and 2017-I2M-3-005).

\section{Availability of data and materials}

The analyzed data sets generated during the study are available from the corresponding author on reasonable request.

\section{Authors' contributions}

YQ and DW performed the experiments. YQ and YC analyzed and interpreted the patient data regarding NPC. LY and HL 
performed the histological examination of NPC. DW and YC were major contributors in writing the manuscript. $\mathrm{YC}$ and WC conceived and designed the experiments. All authors read and approved the final manuscript.

\section{Ethical approval and consent to participate}

The present study was approved by the Institutional Review Board of the Cancer Hospital of the Chinese Academy of Medical Sciences (Beijing, China).

\section{Consent for publication}

Written informed consent was provided by all patients prior to enrollment in the study. The consent was provided by the guardians if they were under 18 years of age.

\section{Competing interests}

The authors declare no potential competing interests regarding this manuscript.

\section{References}

1. Chang ET and Adami HO: The enigmatic epidemiology of nasopharyngeal carcinoma. Cancer Epidemiol Biomark Prev 15: 1765-1777, 2006.

2. Lee AW, Ma BB, Ng WT and Chan AT: Management of nasopharyngeal carcinoma: Current practice and future perspective. J Clin Oncol 33: 3356-3364, 2015.

3. Chua MLK, Wee JTS, Hui EP and Chan ATC: Nasopharyngeal carcinoma. Lancet 387: 1012-1024, 2016.

4. Seliger B, Marincola FM, Ferrone S and Abken H: The complex role of B7 molecules in tumor immunology. Trends Mol Med 14: $550-559,2008$.

5. del Rio ML, Buhler L, Gibbons C, Tian J and Rodriguez-Barbosa JI: PD-1/PD-L1, PD-1/PD-L2, and other co-inhibitory signaling pathways in transplantation. Transpl Int 21: 1015-1028, 2008.

6. Day CL, Kaufmann DE, Kiepiela P, Brown JA, Moodley ES, Reddy S, Mackey EW, Miller JD, Leslie AJ, DePierres C, et al: PD-1 expression on HIV-specific T cells is associated with T-cell exhaustion and disease progression. Nature 443: 350-354, 2006.

7. Balar AV and Weber JS: PD-1 and PD-L1 antibodies in cancer: Current status and future directions. Cancer Immunol Immunother 66: 551-564, 2017.

8. Lin X, Gudgeon NH, Hui EP, Jia H, Qun X, Taylor GS, Barnardo MC, Lin CK, Rickinson AB and Chan AT: CD4 and CD8 T cell responses to tumour-associated Epstein-Barr virus antigens in nasopharyngeal carcinoma patients. Cancer Immunol Immunother 57: 963-975, 2008.

9. Lo YM, Chan LY, Lo KW, Leung SF, Zhang J, Chan AT, Lee JC, Hjelm NM, Johnson PJ and Huang DP: Quantitative analysis of cell-free Epstein-Barr virus DNA in plasma of patients with nasopharyngeal carcinoma. Cancer Res 59: 1188-1191, 1999.

10. Li J, Huang ZF, Xiong G, Mo HY, Qiu F, Mai HQ, Chen QY, He J, Chen SP, Zheng LM, et al: Distribution, characterization, and induction of $\mathrm{CD} 8^{+}$regulatory $\mathrm{T}$ cells and IL-17-producing $\mathrm{CD}^{+} \mathrm{T}$ cells in nasopharyngeal carcinoma. J Transl Med 9: 189, 2011.

11. Lin DC, Meng X, Hazawa M, Nagata Y, Varela AM, Xu L, Sato Y, Liu LZ, Ding LW, Sharma A, et al: The genomic landscape of nasopharyngeal carcinoma. Nat Genet 46: 866-871, 2014.
12. Apetoh L, Ghiringhelli F, Tesniere A, Obeid M, Ortiz C, Criollo A, Mignot G, Maiuri MC, Ullrich E, Saulnier P, et al: Toll-like receptor 4-dependent contribution of the immune system to anticancer chemotherapy and radiotherapy. Nat Med 13: 1050-1059, 2007.

13. Chen L and Flies DB: Molecular mechanisms of T cell co-stimulation and co-inhibition. Nat Rev Immunol 13: 227-242, 2013.

14. Lim DY, Tanaka Y, Iwasaki M, Gittis AG, Su HP, Mikami B, Okazaki T, Honjo T, Minato N and Garboczi DN: The PD-1/PD-L1 complex resembles the antigen-binding Fv domains of antibodies and T cell receptors. Proe Natl Acad Sci USA 105: 3011-3016, 2008.

15. Chang DY, Song SH, You S, Lee J, Kim J, Racanelli V, Son H and Shin EC: Programmed death-1 (PD-1)-dependent functional impairment of CD4( $\left(^{+}\right) \mathrm{T}$ cells in recurrent genital papilloma. Clin Exp Med 14: 305-313, 2014.

16. Muenst S, Schaerli AR, Gao F, Däster S, Trella E, Droeser RA, Muraro MG, Zajac P, Zanetti R, Gillanders WE, et al: Expression of programmed death ligand 1 (PD-L1) is associated with poor prognosis in human breast cancer. Breast Cancer Res Treat 146: 15-24, 2014.

17. Frigola X, Inman BA, Lohse CM, Krco CJ, Cheville JC, Houston TR, Leibovich B, Blute ML, Dong H and Kwon ED: Identification of a soluble form of B7-H1 that retains immunosuppressive activity and is associated with aggressive renal cell carcinoma. Clin Cancer Res 17: 1915-1923, 2011.

18. Maine CJ, Aziz NH, Chatterjee J, Hayford C, Brewig N, Whilding L, George AJ and Ghaem-Maghami S: Programmed death ligand-1 over-expression correlates with malignancy and contributes to immune regulation in ovarian cancer. Cancer Immunol Immunother 63: 215-224, 2014.

19. Azuma K, Ota K, Kawahara A, Hattori S, Iwama E, Harada T, Matsumoto K, Takayama K, Takamori S, Kage M, et al: Association of PD-L1 overexpression with activating EGFR mutations in surgically resected nonsmall-cell lung cancer. Ann Oncol 25: 1935-1940, 2014.

20. Peng H, Zhong BL, Li YM, Wang GM and Chen YY: Expression and significance of costimulatory molecule PD-L1 in nasopharyngeal carcinoma. J Trop Med 12: 1367-1368, 2012.

21. Shi SJ, Wang LJ, Wang GD, Guo ZY, Wei M, Meng YL, Yang AG and Wen WH: B7-H1 expression is associated with poor prognosis in colorectal carcinoma and regulates the proliferation and invasion of HCT116 colorectal cancer cells. PLoS One 8: e76012, 2013

22. Nomi T, Sho M, Akahori T, Hamada K, Kubo A, Kanehiro H, Nakamura S, Enomoto K, Yagita H, Azuma M and Nakajima Y: Clinical significance and therapeutic potential of the programmed death-1 ligand/programmed death-1 pathway in human pancreatic cancer. Clin Cancer Res 13: 2151-2157, 2007.

23. Li YF, Ding JW, Liao LM, Zhang ZL, Liao SS, Wu Y, Zhou DY, Liu AW and Huang L: Expression of programmed death ligand-1 predicts poor outcome in nasopharyngeal carcinoma. Mol Clin Oncol 7: 378-382, 2017.

24. Song Y, Xiao H, Yang Z, Geng M, Ma J, Ren Y, Liu Y and Wang G: The predictive value of pre- and post-induction chemotherapy plasma EBV DNA level and tumor volume for the radiosensitivity of locally advanced nasopharyngeal carcinoma. EXCLI J 16: 1268-1275, 2017.

25. Topalian SL, Hodi FS, Brahmer JR, Gettinger SN, Smith DC, McDermott DF, Powderly JD, Carvajal RD, Sosman JA, Atkins MB, et al: Safety, activity, and immune correlates of anti-PD-1 antibody in cancer. N Engl J Med 366: 2443-2454, 2012.

26. Hamid O, Robert C, Daud A, Hodi FS, Hwu WJ, Kefford R Wolchok JD, Hersey P, Joseph RW, Weber JS, et al: Safety and tumor responses with lambrolizumab (anti-PD-1) in melanoma. N Engl J Med 369: 134-144, 2013.

27. Brahmer JR, Tykodi SS, Chow LQ, Hwu WJ, Topalian SL, Hwu P, Drake CG, Camacho LH, Kauh J, Odunsi K, et al: Safety and activity of anti-PD-L1 antibody in patients with advanced cancer. N Engl J Med 366: 2455-2465, 2012. 